Check for updates

Epidemic Intelligence Center, Taiwan Centers for Disease Control, Taipei, Taiwan

2 Department of Epidemiology of Microbial Diseases and the Public Health Modelling Unit, Yale School of Public Health, New Haven, CT, USA

3 Institute of Epidemiology and Preventive Medicine, National Taiwan University College of Public Health, Taipei 10055, Taiwan

Correspondence to: $\mathrm{H}-\mathrm{H}$ Lin hsienho@ntu.edu.tw

Cite this as: BMJ2021;372:n822 http://dx.doi.org/10.1136/bmj.n822 Published: 31 March 2021

\section{Test, trace, and isolate in the UK}

\section{Gaps in adherence undermine effectiveness at every stage}

\author{
Hao-Yuan Cheng, ${ }^{1}$ Ted Cohen, ${ }^{2}$ Hsien-Ho Lin ${ }^{3}$
}

Test, trace, and isolate programmes are important interventions for the control of infectious disease epidemics, especially those associated with emerging pathogens. However, successful implementation of such a programme requires a series of coordinated efforts. Using data from 37 national online surveys, Smith and colleagues (doi:10.1136/bmj.n6o8) report the performance of the test, trace, and isolate system in the UK over the initial 11 months of the covid-19 pandemic. ${ }^{1}$ The authors examined each major component of the programme and analysed the factors associated with gaps within each component.

What do the results of this study tell us about the implementation of the covid-19 test, trace, and isolate system in the UK? The simple math is revealing: 50\% of respondents could identify the symptoms of covid-19, 20\% would seek a test for covid-19 if they had symptoms, and $80 \%$ would share details of close contacts if they tested positive. Taken together, if respondents were a representative sample of people with symptoms, the contacts of only $8 \%$

$(50 \% \times 20 \% \times 80 \%)$ of all people with symptoms of covid-19 would be identifiable and therefore eligible for subsequent isolation and quarantine efforts. Since the basic reproduction number of covid-19 is estimated to be between 2 and 3 or even higher, at least 50-66\% of transmissions would need to be interrupted to bring the effective reproduction number below the critical threshold of $1 .^{23}$ The persistent gaps in the UK's test, trace, and isolate system reported by Smith and colleagues suggest that the programme probably had only a limited impact on the pandemic in the UK.

The data gathered in this study, which reveal large gaps in both symptom recognition and willingness to test, suggest that investments in health communication to improve knowledge of symptoms and to reduce barriers to diagnostic testing could have been more effective than investments in training contact tracers. Context is important, however. The situation might be different outside the UK, and extrapolation is difficult.

A test, trace, and isolate programme that targets symptomatic covid-19 infections in the population has additional limitations when transmission from asymptomatic and pre-symptomatic infections occurs frequently. Studies of the transmission dynamics of covid-19 have shown that pre-symptomatic transmission accounts for a high proportion (up to $40 \%$ ) of all transmissions..$^{-6}$ Furthermore, identification of close contacts must be followed by quarantine of those contacts-an additional potential gap that is not directly addressed in the linked analysis.
The true impact of a test, trace, and isolate programme is probably even lower than that suggested by Smith and colleagues' findings, given the extent of pre-symptomatic and asymptomatic transmission of covid-19 and the potential for attrition along the full cascade of test, trace, and isolate efforts. Ultimately, symptom based and case based interventions alone are highly unlikely to contain the covid-19 pandemic. A more realistic expectation is that an effective test, trace, and isolate programme can be one component of a more comprehensive strategy. Population based measures such as physical distancing, use of face masks, and possibly mass testing are needed to complement case based interventions to reduce the reproduction number to below unity-as has been observed in settings such as Singapore and Taiwan.

Even now, vaccines are not anticipated to bring life back to normal quickly, and concerns about vaccine safety ${ }^{7}$ and viral variants pose ongoing challenges for vaccination programmes globally. Combined use of vaccination, case based interventions, and population based interventions provide the best chance for sustained control of covid-19. The study by Smith and colleagues is an important reminder of the gaps and vulnerabilities associated with test, trace, and isolate programmes.

Looking ahead, innovative approaches, including digital contact tracing, promise to make more efficient use of resources and to improve the efficacy of test, trace, and isolate in a resource constrained public health system, but the on-the-ground effectiveness of such approaches has yet to be thoroughly evaluated. ${ }^{8}$

Competing interests: The BMJ has judged that there are no disqualifying financial ties to commercial companies. The authors declare the following other interests: none.

The BMJ policy on financial interests is here: https://www.bmj.com/sites/default/files/attachments/resources/2016/03/16-current-bmj-education-coi-form.pdf.

Provenance and peer review: Commissioned; not externally peer reviewed.

Smith LE, Potts HWW, Amlôt R, Fear NT, Michie S, Rubin GJ. Adherence to the test, trace, and isolate system in the UK: results from 37 nationally representative surveys. BMJ2021;372:n608.

2 Cowling BJ, Ali ST, Ng TWY, etal. Impact assessment of non-pharmaceutical interventions against coronavirus disease 2019 and influenza in Hong Kong: an observational study. Lancet Public Health 2020;5:e279-88. doi: 10.1016/S2468-2667(20)30090-6 pmid: 32311320

3 Kissler SM, Tedijanto C, Goldstein E, Grad YH, Lipsitch M. Projecting the transmission dynamics of SARS-CoV-2 through the postpandemic period. Science 2020;368:860-8. doi: 10.1126/science.abb5793 pmid: 32291278

Nishiura $\mathrm{H}$, Linton NM, Akhmetzhanov AR. Serial interval of novel coronavirus (COVID-19) infections. Int J Infect Dis 2020;93:284-6. doi: 10.1016/j.ijid.2020.02.060 pmid: 32145466 
5 Cheng H-Y, Jian S-W, Liu D-P, Ng TC, Huang WT, Lin HHTaiwan COVID-19 Outbreak Investigation Team. Contact Tracing Assessment of COVID-19 Transmission Dynamics in Taiwan and Risk at Different Exposure Periods Before and After Symptom Onset. JAMA Intern Med 2020;180:1156-63. doi: 10.1001/jamainternmed.2020.2020 pmid: 32356867

6 Ferretti L, Ledda A, Wymant C, etal. The timing of COVID-19 transmission.medRxiv 2020;2020.09.04.20188516. http://medrxiv.org/content/early/2020/09/16/2020.09.04.20188516

7 European Medicines Agency. COVID-19 Vaccine AstraZeneca: benefits still outweigh the risks despite possible link to rare blood clots with low blood platelets www.ema.eu-

ropa.eu/en/news/covid-19-vaccine-astrazeneca-benefits-still-outweigh-risks-despite-possiblelink-rare-blood-clots

8 Cebrian M. The past, present and future of digital contact tracing. Nat Electron 2021:4:2-4. doi: 10.1038/s41928-020-00535-z.

This article is made freely available for use in accordance with BMI's website terms and conditions for the duration of the covid-19 pandemic or until otherwise determined by BMI. You may use, download and print the article for any lawful, non-commercial purpose (including text and data mining) provided that all copyright notices and trade marks are retained. 